\title{
Peripartum cardiomyopathy and ventricular thrombus: A case report and review of literature
}

\author{
Ugur Aksu, ${ }^{1}$ Selim Topcu, ${ }^{2}$ Oktay Gulcu, ${ }^{2}$ Ibrahim Halil Tanboga ${ }^{2}$ \\ ${ }^{1}$ Department of Cardiology, Bursa State Hospital, Bursa, Turkey \\ ${ }^{2}$ Department of Cardiology, Atatürk University Faculty of Medicine, Erzurum, Turkey
}

\begin{abstract}
Peripartum cardiomyopathy (PPCMP) is a rare and life-threatening condition. Intracardiac thrombus is characteristically associated with increased adverse events, mortality, and a high risk of thromboembolic events, and has been associated with PPCMP. Early diagnosis and treatment play a critical role. Although echocardiography is the first-line diagnostic method, other imaging modalities may provide useful information in appropriate patients. Presently described is a case in which an apical intracardiac thrombus coexisting with PPCMP was identified and managed using multimodality imaging studies.
\end{abstract}

Keywords: Congestive heart failure; dilated cardiomyopathy; thrombus.

Cite this article as: Aksu U., Topcu S., Gulcu O., Tanboga I. H. TPeripartum cardiomyopathy and ventricular thrombus: A case report and review of literature. North Clin Istanb 2018;5(2):145-147.

$\mathrm{P}$ eripartum cardiomyopathy (PPCMP) is a rare disease, which can present between the final months of pregnancy and the $6^{\text {th }}$ postpartum week and can lead to heart failure. Intracardiac thrombus is characteristically associated with a high risk of thromboembolic events and reported as an additional finding together with PPCMP. Transthoracic echocardiography (TTE) is a very important diagnostic modality for both of these entities [1-4]. Although most of the literature relies exclusively on TTE findings for diagnosis, we report a case, in which an apical intracardiac thrombus coexisting with PPCMP was identified and managed using multimodality imaging studies.

\section{CASE REPORT}

A 25-year-old female patient presented to the emergency room with dyspnea and markedly reduced effort capacity. Medical history was notable for an uneventful pregnancy and normal delivery of a healthy baby 1 week prior to presentation. Dyspnea on exertion started on the $2^{\text {nd }}$ postpartum day, progressed, and the patient reported paroxysmal nocturnal dyspnea for 3 nights. Her admission vitals were normal except tachypnea and a relatively low oxygen saturation (93\%). Physical examination revealed general pallor, bibasilar rales, and $\mathrm{S} 3$. Electrocardiography showed sinus tachycardia. Ventricular dilatation, increased ventricular filling pressure, moderate systolic dysfunction, and moderate mitral regurgitation were found on TTE, together with an $\mathrm{PAB}$ of $40 \mathrm{mmHg}$. A hypoechoic mass with irregular borders concurrent with a thrombus was apparent in the left ventricle (Fig. 1). Liver and kidney function tests were within normal limits; brain natriuretic peptide and Ddimer levels were high. Autoimmune panel and thyroid function tests were normal.

Patient was admitted to the coronary care unit with presumed diagnoses of peripartum cardiomyopathy and an apical thrombus. Diuresis and heparinization were initiated. Cardiac tomography scan (CTC) was planned

Received: January 19, 2017 Accepted: July 24, 2017 Online: March 30, 2018

Correspondence: Dr. Ugur AKSU. Department of Cardiology, Bursa State Hospital, Bursa, Turkey.

Phone: +90 5417875725 e-mail: aksuuu001@msn.com

(c) Copyright 2018 by Istanbul Provincial Directorate of Health - Available online at www.northclinist.com 


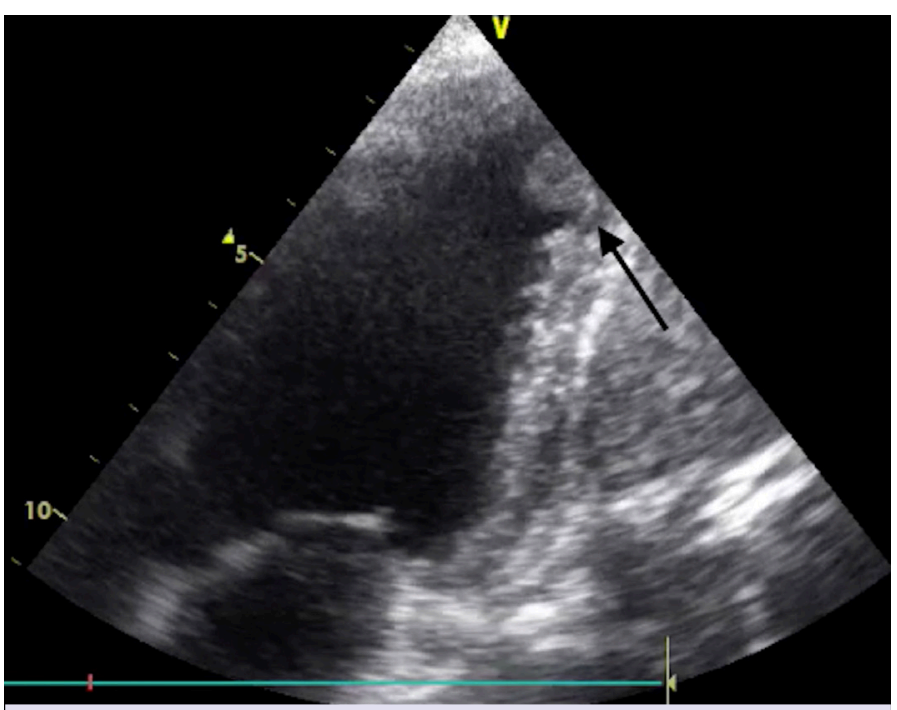

FIGURE 1. A hypoechoic mass with irregular borders concurrent with a thrombus based on the apical two-chamber view

to investigate the accompanied cardiac anomaly causing ventricular thrombus development, and apical cardiac thrombus was confirmed (Fig. 2a, b). On the $3^{\text {rd }}$ day of admission, a control TTE showed that the embolus had diminished in size. To exclude coronary heart disease, invasive coronary angiography (ICA) was scheduled, and ICA performed on the $5^{\text {th }}$ day revealed a normal coronary artery (Fig. 3) concurrent with peripartum cardiomyopathy. Patient was maintained on diuretics and coumadin and was discharged on the $10^{\text {th }}$ day of admission. Control TTE in the $1^{\text {st }}$ month showed improvement of ventricular diameters, absence of embolus, and an EF of $50 \%$. Patient was maintained on anticoagulation and $1^{\text {st }}$ year TTE was within normal limits. Patient was counseled for further pregnancies and increased risk of cardiac and thromboembolic events.
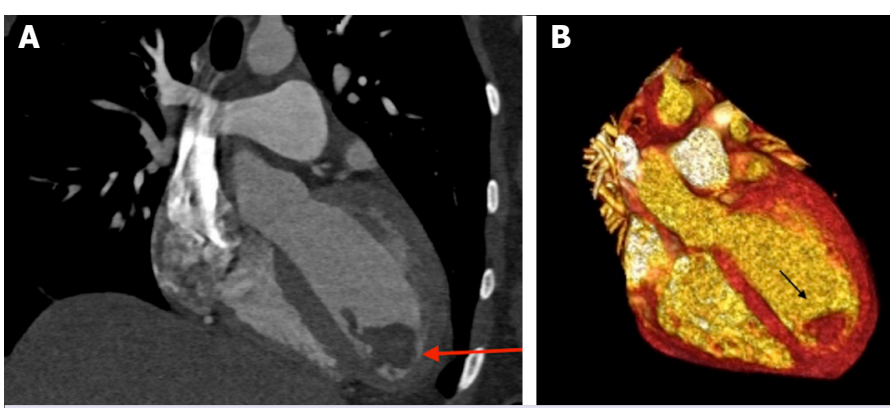

FIGURE 2. Two-dimensional (A) and three-dimensional (B) tomography scan with volume rendering showed large ventricular thrombus

\section{DISCUSSION}

Exact incidence of peripartum cardiomyopathy is not known, and reported incidence varies between $1 / 15000$ and $1 / 3000$ due to population heterogeneity. TTE is the most common modality used for diagnosis of PPCMP. Dilated ventricles and reduced ejection fractures are commonly seen. Most established risk factors are age older than 30 years, multiple gestations, hypertension during pregnancy, and conduction defects. Late presentation after delivery is a sign of bad prognosis $[5,6]$.

Blood volume increases progressively and peaks at a high of $150 \%$ of normal at the last trimester during pregnancy. In the absence of cardiac failure, this situation is well tolerated, but during delivery, stress, pain, uterine contractions, and relief of pressure from IVC post-delivery, all serve to increase preload, further burdening the myocardium. In nearly $50 \%$ of cases, PPCMP coexists with ventricular thrombus. Ventricular thrombus causes thromboembolic events in majority of cases. In our case, shortness of breath and decreased effort capacity were not present before or immediately after the delivery. This fact is concurrent with established literature regarding PPCMP $[7,8]$.

Pregnancy is a hypercoagulable state due to increased levels of factor 7, 8, 10-fibrinogen as well as platelet activity. This state can last until 6 weeks postpartum and is the main reason underlying the development of thrombi. Also, the volume stasis due to cardiac failure further predisposes patients to cardiac emboli, as shown by various case reports describing peripheral and central thromboemboli, during pregnancy $[5,6,9]$. Because the patient described here had a negative autoimmune/viral panel and no history of medication or alcohol use and the properties of the ventricular thrombus itself (hypoechoic, irregular
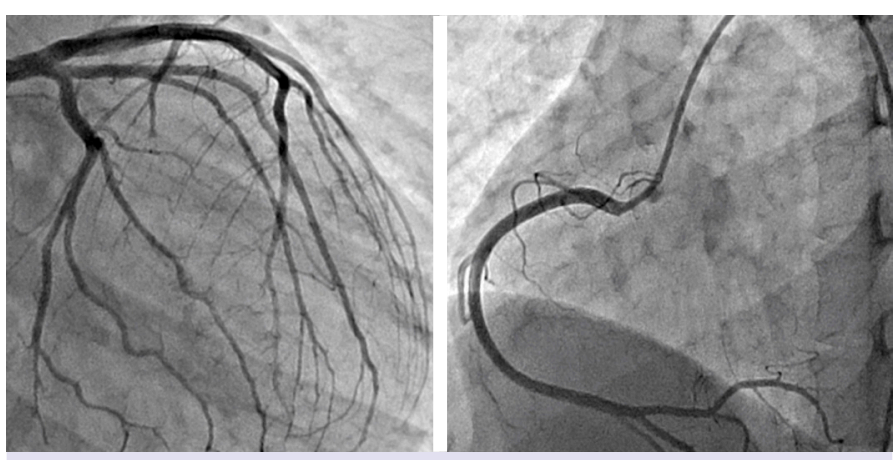

FIGURE 3. ICA showed no evidence of obstructive coronary artery disease concurrent with peripartum cardiomyopathy 
borders, and pedunculated) most likely pointed to a de novo thrombus, we consider that it was precipitated by PPCMP and not as a result of a pre-existing process.

There is no consensus on the duration of anticoagulation treatment in a patient with PPCMP and ventricular thrombus. Our patient had complete resolution of the ventricular thrombus on TTE in the $1^{\text {st }}$ month, with mostly normalized cardiac function. We ultimately decided to provide lifelong anticoagulation based on the patient's perfect compliance to the medical therapy and absence of side effects.

\section{CONCLUSION}

PPCMP is the most frequently encountered reason for cardiac failure in the medium term postpartum period. The stasis induced by cardiac failure and the hypercoagulable state of pregnancy may easily lead to cardiac thrombus. Cardiac thrombus is a source of serious morbidity and mortality in this patient population. Early diagnosis, confirmation, and follow-up with appropriate modalities and prompt start of treatment are the main targets when confronted with such situations.

Informed Consent: Written informed consent was obtained from the patient who participated in this study.

Conflict of Interest: No conflict of interest was declared by the authors.

Financial Disclosure: The authors declared that this study has received no financial support.
Authorship contributions: Concept - U.A.; Design - I.H.T.; Supervision - S.T.; Materials - O.G.; Data collection \&/or processing - U.A.; Analysis and/or interpretation - I.H.T.; Writing - U.A.; Critical review - U.A.

\section{REFERENCES}

1. Abboud J, Murad Y, Chen-Scarabelli C, Saravolatz L, Scarabelli TM. Peripartum cardiomyopathy: a comprehensive review. Int J Cardiol 2007;118:295-303. [CrossRef]

2. Shimamoto T, Marui A, Oda M, Tomita S, Nakajima H, Takeuchi T, Komeda M. A case of peripartum cardiomyopathy with recurrent left ventricularapical thrombus. Circ J 2008;72:853-4. [CrossRef]

3. Altuwaijri WA, Kirkpatrick ID, Jassal DS, Soni A. Vanishing left ventricular thrombus in a woman with peripartum cardiomyopathy: a case report. BMC Res Notes 2012;5:544. [CrossRef]

4. Kharwar RB, Chandra S, Dwivedi SK, Saran RK. A pedunculated left ventricular thrombus in a women with peripartum cardiomyopathy: evaluation by three dimensional echocardiography. J Cardiovasc Ultrasound;22:139-43. [CrossRef]

5. Arany Z, Elkayam U. Peripartum Cardiomyopathy. Circulation 2016;133:1397-409. [CrossRef]

6. Hilfiker-Kleiner D, Haghikia A, Nonhoff J, Bauersachs J. Peripartum cardiomyopathy: current management and future perspectives. Eur Heart J 2015;36:1090-7. [CrossRef]

7. Gutterman DD, Ayres RW. Use of echocardiography in detecting cardiac sources of embolus. Echocardiography 1993;10:311-20. [CrossRef]

8. Bauersachs J, Arrigo M, Hilfiker-Kleiner D, Veltmann C, Coats AJ, Crespo-Leiro MG, et al. Current management of patients with severe acute peripartum cardiomyopathy: practical guidance from the Heart Failure Association of the European Society of Cardiology Study Group on peripartum cardiomyopathy. Eur J Heart Fail 2016;18:1096-105.

9. Koç M, Sahin DY, Tekin K, Caylı M. Development of biventricular large apical thrombi and cerebral embolism in a young woman with peripartum cardiomyopathy. Turk Kardiyol Dern Ars 2011;39:591-4. 